(NASA-CR-200039) VLBI DATA, ACQUISITION, ENVIRONMENTAL EFFECTS (MIT) $4 \mathrm{P}$

N96-17832

Unclas

$63 / 43 \quad 0098268$ 


\title{
VLBI data, acquisition, environmental effects
}

\author{
Thomas A Herring \\ Department of Earth, Atmospheric, and Planetary Sciences. Massachusetts Institute of \\ Technology, Cambridge
}

\section{Introduction}

During this quadrennium, very long baseline interferometry (VLBI) data acquisition and system development has focused on improving the accuracy of the system sufficiently to allow the determination of reliable estimates of height variations. Associated with this aim has been improvements in the determinations of horizontal velocity fields, monitoring water vapor delay using interferometric methods, and improvements to Earth' rotation measurements. The primary aims of the improvements to height measurement accuracy have been to directly measure the contemporary magnitudes of post glacial rebound, and to determine a height reference system for measuring global sea level rise. High frequency Earth rotation studies have been carried out to better define the transformation parameters from an inertial coordinate system to an Earth fixed one, and to better understand the coupling between tre components of the atmosphere-ocean-solid Earth system. Two major VLBI campaigns were carried out in support of these studies: (1) Epoch-92 in July 1992 and (2) Cont94 in January 1994. Each of these campaigns lasted approximately two-weeks and involved multiple VLBI networks operating simultaneously in addition to other space geodetic systems operating during these periods.

Two major compilations of the VLBI resuits (and results from other space geodetic systems) have been published during this quadrennium. The proceedings from the Chapman conference on Geodetic VLBI Monitoring Global Change [Carter, 1991] provides a summary of the status of the accuracy, expected improvements to, and the applications of VLBI to monitoring global change circa 1991. The other major compilation was the three volume monograph on contributions of space geodesy to geodynamics (Smith and Turcotte, 1993). These three volumes provide a comprehensive summary of the results obtained from the NASA Crustal Dynamics Project.

\section{System improvements: Understanding the VLBI error spectrum}

Recent developments in VLBI instrumentation have been aimed at achieving millimeter accurate station coordinates with one-day measurement durations. The

Copyright 1995 by the American Geophysical Union.

Paper number 95RG00349. 8755-1209/95/95RG-00349\$15.00

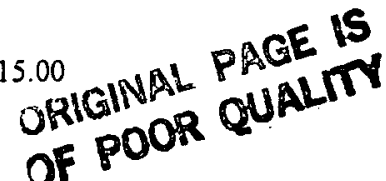

Mark III VLBI system consists of electronics io amplify and frequency shift the very weak signals from extragalatic radio sources so that they can be recorded on wide bandwidth tape recorders. Associaled with the Mark III VLBI system is a correlator s:siem which can play back the recorded tapes, cross correlate the signals, and determine accurately the cifferences in arrival times (group delays), in phase (phase delays), and in Doppler shift (phase delay rates) of ihe signals recorded on the tapes. The deveiopments to this system have been to improve (1) group-delay data accuracy; (2) observing schedules; (3) a:mospheric delay modeling; and (4) combination of dala. The primary enhancements to Mark III instrumentation to achieve higher-accuracy group-delay measuremenss a:e widening of the synthesized bandwidth Corey and Clark, 1991); increasing the recorded bandwicth of the signal, which also includes the Mark IV VLBI developments [Whitney et al., 1991]; and improving the delay calibrations through the VLBI receiving and recording systems [Rogers, 1991]. Overviews of these improvements are reported by Rogers [1991) and Rogers et al. [1993]. The implementation of the these system improvements have made group-delay measurements with uncertainties of $\leq 5 \mathrm{~mm}$ routine for modern VLBI systems.

The schedules for making VLBI observations (i.e., the choice of which quasars to observe, with which antenna, and for what duration for each observation) have also been improved over the last few years. Davis et al. [1991] reported on improved baseline length measurements through the use of observations made at lowelevation angles (as low as 5 degrees) and the use of low elevation angle observations is now routine in VLBI experiments. Another important enhancement in the scheduling has been making the azimuth coverage at each station as uniform as possible [Niell, 1991].

With the increased use of low elevation angle data in VLBI experiments there has been recent improvements to atmospheric delay models. The models have sought to improve the low elevation angle performance of the functions that relate the atmospheric zenith delay to the line of sight delay; the so called mapping functions. Herring $[1992$ a $]$ reports on a new series of mapping functions based on the analysis of radiosonde data that takes advantage of the continued fraction in sine of elevation angle to parameterize the mapping function. (The continued fraction has in its denominator sine of elevation angle plus a small parameterized number which has as its denominator sine of elevation angle plus another a small parameterized number or so on. Three levels of continued fraction is sufficient to parameterize the mapping function.) These mapping functions use the sur- 
face temperature projected from the temperature profile below the tropopause as a proxy for the seasonal variation in atmospheric parameters. These new mapping functions have root mean square (RMS) errors of typically $30 \mathrm{~mm}$ at 5 degrees elevation angle for the hydrostatic delay and $10 \mathrm{~mm}$ RMS at 5 degrees elevation for the wet delay. These errors are about half the size of the errors in previous generation models. There has also been increased study of the effects of atmospheric gradients with results being reported in (Herring, $1992 a_{\text {; }}$ Davis, 1992; Rogers et al., 1993; and Davis et al., 1993]. Some of these studies have used water vapor radiometers to study the variations in water vapor delay as the radiometer is scanned in azimuth at a fixed elevation angle. Others have used estimates of the gradients from the analysis of the VLBI data (i.e., gradient parameters are estimated along with other geodetic parameters). In both cases, the magnitudes of gradients are similar and typically result in a departure from azimuthal symmetry of $10 \mathrm{~mm}$ at 5 degrees elevation angle. In some cases the departure from azimuthal symmetry at 5 degrees elevation angle can reach $100 \mathrm{~mm}$. Uncorrected, a persistent gradient of $10 \mathrm{~mm}$ at 5 degrees elevation angle could result in a horizontal errors of the same magnitude.

Several studies have also been carried out to assess the utility of water vapor radiometers for calibrating the most variable and least predictable component of the atmospheric delay. The two largest studies [Elgered et al., 1991; and Kuehn et al., 1991) used water vapor radiometer data collected over intervals between 3 to 10 years and compared the RMS repeatability of baseline lengths obtained from the best stochastic solutions not using the WVR data with the best analyses using the WVR data. In both studies it was concluded that for WVR data to be useful, accurate surface pressure measurements are needed to calibrate the hydrostatic delay and no low elevation angle data ( $<20$ degrees) should be included in the analysis. In the analyses using WVR data, no atmospheric parameters are estimated. The most recently collected WVR data improves the baseline length RMS over the best stochastic solutions but the improvement is less than $10 \%$. In both studies, there were anomalous biases of up to $10 \mathrm{~mm}$ amplitudes between the atmospheric delay estimates inferred from the WVR data and those estimated from the VLBI data. These studies could not resolve the influence of mapping function errors on the stochastic estimates and the effects of biases in the WVR measurements and on the conversion of WVR sky temperature measurements to delays. An additional study was carried comparing VLBI and Global Positioning System (GPS) estimates of atmospheric delays [Tralli, et al., 1992]. Here the differences between the VLBI and GPS estimates were typically $\leq 10 \mathrm{~mm}$ and comparable to or smailer than the differences seen between VLBI and WVR's. In general, all of these studies indicate resicual atmospheric delay modeling errors of $10 \mathrm{~mm}$ and less, but errors of this magnitude can induce errors in heignt estimates by up $30 \mathrm{~mm}$. There have been no recent extensive com- parisons of WVR's and VLBI primarily because of lack of WVR data.

The performance of VLBI measurements as reported in Rogers et al. [1993] for circa 1992 measurements was $5 \mathrm{~mm}+2$ parts-per-billion ( $\mathrm{ppb}$ ) implying height measurements precisions of about $25 \mathrm{~mm}$. Recent VLBI measurements from January 1994 indicate that the highest quality VLBI experiment have achieved precisions of $1 \mathrm{~mm}+0.7 \mathrm{ppb}$ implying height precisions of about 9 mm [Clark et al., 1994]. All of the improvements discussed above seem to have played equal roles in this improvement. Results of this quality should be capable of addressing numerous questions about post glacial rebound and for defining a global reference systems for measuring global sea level rise.

\section{Global sea level and Post glacial rebound}

The primary reporting of the contributions VLBI could make to global change studies was through the NOAA Chapman conference [Carter, 1991]. Douglas [1991], Sloss [1991] and Douglas [1992) discuss the contributions that VLBI measurements, with sufficient accuracy, could make to the establishing a global height reference frame and conclude that a verification and possible modification of existing post glacial rebound models would be one method for allowing contemporary solid Earth motions to be deconvolved from existing tide gauge estimates of the global sea level rise. There have been recent studies comparing VLBI measurements at northern latitude sites with the expected signals from post glacial rebound. Tushingham [1991] discusses the effects to be expected and Mitrovico et al. [1993], James and Lambert [1993], and Mitrovice et al. [1994] all report on the comparison of VLBI measurements with the signals both in the horizontal and vertical directions expected from post glacial rebound. All of these studies indicate that the precision in height rates of change or of baseline length rates of the change is not yet sufficient to make any definitive statements about the current accuracy of post glacial rebound models. Although there is strong evicence building that the VLBI site at. Algonquin Canada is moving at a rate of a few $\mathrm{mm} / \mathrm{yr}$ under the influence of post glacial rebound relative the VLBI sites in eastern North America at lower latitudes [Ryan et al., 1993l.

The viability of VLBI to make definitive height measurements has been addressed by vanDam and Herring [1994] and MacMillan and Gipson [1994] by searching for the elastic deformation of the Earth's surface due to changes in atmospheric pressure loading (RMS amplitude of $\leq 5 \mathrm{~mm}$ ) which should be seen in VLBI height measurements. Both studies indicate that only about $60 \%$ of the expected atmospheric loading signal is present in the VLBI measurements indicating either errors in the VLBI measurements that are anticorrelated with the loading signal or noise in the estimates of the loading signals. Anticorrelated signals might be expected through atmospheric delay modeling errors be- 
cause of possible gradients in the atmospheric delay associated with the passage of pressure fronts which themselves cause most of the changes in the loading signal. Some combination of both reasons is likely. In both studies, it was concluded that atmospheric loading is currently a small percentage $(\leq 20 \%)$ of the noise on VLBI height measurements. For the most recent VLBI data with improved vertical precision this percentage could rise to as much as $50 \%$.

In another study of the ability of VLBI to maintain a long term reference system, Herring [1992b] reports of submillimeter repeatability of the relative positions of a pair of radio telescopes in Massachusetts over a 20 year interval as a measure of the long stability of the radio telescopes. The conclusion from this study was that despite the size of VLBI radio telescopes, long term stability of the reference point appear adequate for making submillimeter per year velocity measurements over long periods of time. In another study of accuracy, Ray et al. [1991] reports on the comparison of VLBI and satellite laser ranging results and confirmed agreement between the two systems at about the $10 \mathrm{~mm}$ level.

\section{Contemporary plate motion and regional tectonic analyses}

The long history of VLBI measurements in tectonically active regions have been used in a number of studies to assess the accumulation of strain in these regions. Many of these studies have been based on the annually released analyses of VLBI data provided by the Goddard Space Flight Center (GSFC) VLBI group; the latest being given in Ryan et al. [1993!. These analyses have been used by Argus and Gordon i1991! to study Sierra Nevada-North America motion; by Argus and Lyzerga [1993] to study deformation associated with subduction at the Japan Trench; and Lisowski [1991\} as part of a study of global plate motions. Studies that used independent analyses of the VLBI cata inciude Fallon and Dillinger [1992) which examised global piate motions; and Feigl et al. (1993i whic: used a rigorous combination of VLBI and GPS data in Southern California to build a kinematic cescription of the accumulation of strain in that region from :934-:992.

\section{High frequency Earth rotation analyses}

The increased accuracy of VLBI measurements over the past few years has lead to the exiension of many of the models of the motion of the Earth in inertial space. In particular, there have now been a number of studies reporting on the detection of tically coherent Earth rotation rate and pole position variations in the diurnal and semidiurnal bands iHerring, 1993; Sovers et al., 1993; Freedman et al., 1994; Herring and Dong, 1994]. The magnitudes of these signa!s can reach 80 microseconds for Universal Time (UT1) and 600 microarc- seconds for pole positions corresponding to surface displacements of $20-30 \mathrm{~mm}$ at the Earth's surface. In this regard, accounting for these variations is important for achieving the highest accuracy geodetic parameter estimates. To further understand, the high frequency variations in Earth rotation, two intense VLBI campaigns that featured continuous VLBI experiments for two weeks have been organized in July 1992 (Epoch-92) and January 1994 (Cont-94). Results from the Epoch92 campaign have been published in a number of different locations and the results from the campaign summarized in Dickey and Feissel [1994]. Only preliminary analyses of the Cont-94 campaign results have been carried out so far but the campaign appears to have generated a very high quality data set.

Acknowledgments. This work was supported by the National Aeronautics and Space Administration under grant NAG 5-538 and NAW-0037, by the National Oceanic and Atmospheric Administration under grant NA90AA-D-AC481, and by the Kerr-McGee Foun-dation. The views expressed herein are those of the authors and do not necessarily reflect the views of NOAA or any of its subagencies.

\section{References}

Argus, D. F. and R. G. Gordon, Current Sierra NevadaNorth America motion from very long baseline interferometry: Implications for the kinematics of the western United States, Geology, 19, 1085-1088. 1991.

Argus, D. F. and G. A. Lyzeng 3 : Constraints on interseismic deformation at Japan Trenci from VLBI data, Geophys. Res. Lett., 20,611-614, 1993.

Carter, W. E. (editor), Proceedings of the Chapman conference on Geodetic VLBI: Monitoring Global Change, NOAA Technical Report NOS 137 NGS 49, pp. 437, 1991.

Clark, T. A., N. R. Vandenberg, and C. C. Thomas, CONT94: 15 days of continuous VLBI. Eos Trans. AGU, 75, 111, 1994.

Corey, B. E. and T. A. Clark, The RF bandwidth upgrade: Doubling the X-band spanned bandwidth of geodetic VLBI Receiving systems, in Proceedings of the Chapman Conference on Geode:ic VIBI: Monitoring Global Change, edited by W. E. Carier, NOA.A Tech. Rep., NOS 137 NGS 49, 15-23, 1991.

Davis, J. L., The effeet of turbulence on atmospheric gradient parameters estimated frem ground-based radiometric and space geodetic measurements, Geophys. Res. Lett., 19, 2183-2186, 1992.

Davis, J. L., G. Elgered, A. E. Niell and C. E. Kuehn, Ground-based measurement of gradients in the "wet" radio refractivity of air, Radio Sci., 28, 1003-1018, 1993.

Davis, J. L., T. A. Herring and I. I. Shapiro, Effects of atmospheric modeling errors on determinations of baseline vectors from very long baseline interferometry, J. Geophys. Reg., 96, 643-650, 1991.

Dickey, J. O. and M. Feissel, Results from the SEARCH'92 Campaign, IERS Tech. Note No. 16, Obs. de Paris, Paris, France, 1994.

Douglas, B. C., Global Sea Level Rise, J. Geophys. Res., 96, 6981-6992, 1991.

Douglas, B. C., Global Sea Level Acceleration, J. Geophys. Res., 97, 12,699-12,706, 1992.

Elgered, G., J. L. Davis, T. A. Herring and I. I. Shapiro, Geodesy by radio interferometry: Water vapor radiometry for estimation of the wet delay, J. Geophys. Res., 96, $6541-6555,1991$.

Fallon, F. W. and W. H. Dillinger, Crustal velocities from geodetic very long baseline interferometry, J. Geophys. Res., 97, 7129-7136, 1992. 
Feigl, K. L., and 14 others, Space geodetic measurement of crustal deformation in central and southern California, 1984-1992, J. Geophys. Res., 98, 21,677-21,712, 1993.

Freedman, A. P., R. Ibanez-Meier, T. A. Herring, S. M. Lichten, and J. O. Dickey, Subdaily Earth rotation during the Epoch'92 campaign, Geophys. Res. Lett., 21, 769$772,1994$.

Herring, T. A., Modeling Atmospheric Delays in the Analysis of Space Geodetic Data, in Proceeding of Refraction of Transatmospheric Signals in Geodesy, edited by J. C. D. a. T. A. Th.Spoelstra, pp. 157-164, Netherlands Geodetic Commission, Publications on Geodesy, The Hague, Netheriands, $1992 a$.

Herring, T. A., Submillimeter horizontal position determination using very long baseline interferometry, J. Geophys. Res., 97, 1981-1990, 19926.

Herring, T. A., Diurnal and semidiurnal variations in Earth rotation, Adv. Space Res., 13, 11,281-11,290, 1993.

Herring, T. A. and D. Dong, Measurement of diurnal and semidiurnal rotational variations and tidal parameters of Earth, J. Geophys. Res., 99, 18,051 18,072, 1994.

James, T. S. and A. Lambert, A comparison of VLBI data with the ICE-3G glacial rebound model, Geophys. Res. Lett., 20, 871-874, 1993.

Kuehn, C. E.. W. E. Himwich, T. A. Clark and C. Ma, An evaluation of water vapor radiometer data for calibration of the wet path delay in very long baseline interferometry experiments, Radio Sci., 26, 1381-1391, 1991.

Lisowski, M., Recent plate motions and crustal deformation, Rey. Geophys., 29, 162-171, 1@ฐ1.

MacMillan, D. S., and J. M. Gipson. Atmospheric pressure loading parameters from VLBI observations. J. Geophys. Res., 99, 18,081-18,088, 1994.

Mitrovica, J. X., J. L. Davis and I. I. Shapiro, Constraining proposed combinations of ice history and Earth rheology using VLBI determined baseline length aces in North America, Geophys. Res. Lett., 20, 2387-2390, 1993.

Mitrovica, J. X., J. L. Davis and I. I. Shapiro, A spectral formalism for computing three-dimensional detormations due to surface loads 2. Present-day glacial isostatic adjustment, J. Geophys. Res., 99, 7075-7101, 1994.

Niell, A. E., Vertical change and atmospheric correction in VLBI, in Proceedings of the Chapman Conference on Geodetic VLBI: Monitoring Giuba! Change, edited by W. E. Carter, NOAA Tech. Rep., NOS 137 NGS 49, 147$158,1991$.
Ray, J. R., C. Ma, J. W. Ryan, T. A. Clark, R. J. Eanes, M. M. Watkins, B. E. Schutz and B. D. Tapley, Comparison of VLBI and SLR geocentric site coordinates, Geophys. Res. Lett., 18, 231-234, 1991.

Rogers, A. E. E., Instrumentation improvements to achieve millimeter accuracy, in Proceedings of the Chapman Conference on Geodetic VLBI: Monitoring Global Change, edited by W. E. Carter, NOAA Tech. Rep., NOS 137 NGS 49, 1-6, 1991.

Rogers, A. E. E. and 34 others, Improvements in the accuracy of Geodetic VLBI, in Contributions of Space Geodesy to Geodynamics, AGU Geodynamics Series Vol 25, Smith, D. E., and D. L. Turcotte (editors), 47-63, 1993.

Ryan, J. W., C. Ma, and D. S. Caprette, NASA space geodesy program-GSFC data analysis-1992, NASA Tech. Memo. 104572, 471 pp., 1993.

Sloss, L. L., The Tectonic Factor in Sea Level Change: A Countervailing View, J. Geophys. Res., 96, 6609-6617, 1991.

Sovers, O. J., C. S. Jacobs and R. S. Gross, Measuring rapid ocean tidal Earth orientation variations with very long baseline interferometry, J. Geophys. Res., 98, 19,959$19,972,1993$.

Tralli, D. M., S. M. Lichten and T. A. Herring, Comparison of Kalman filter estimates of zenith atmospheric path delays using the Global Positioning System and very long baseline interferometry, Radio Sci., 27, 999-1007, 1992.

Tushingham, A. M., Potential effects of ongoing postglacial adjustment on very long baseline interferometry measurements, Geophys. Res. Lett., 18, 1281-1284, 1991.

vanDam, T. M. and T. A. Herring, Detection of atmospheric pressure loading using very long baseline interferometry measurements,. J. Geophys. Res., 99, 4505-4517, 1994.

Whitney, A. R., A. E. E. Rogers, R. J. Cappallo, J. E. Hargreaves, H. F. Hinteregger, and D. J. Smyrhe, The Mark 4 data-acquisition system, in Proceedings of the Chapman Conference on Geodetic VIBI: Monitoring Global Change, edited by W. E. Carter, NOAA Tech. Rep., NOS 137 NGS $49,7-14,1991$.

T. A. Herring, Department of Earth, Atmospheric, and Planetary Sciences, Massachusetts Institute of Technology, Cambridge, MA 01239

(Received June 10, 1994; accepted November 21, 1994.) 